\title{
MODELAGEM BIM PARA ORÇAMENTAÇÃO COM USO DO SINAPI
}

\author{
BIM MODELLING TO BUDGETING USING SINAPI
}

Felipe Miguel Rocha Andrade ${ }^{1}$, Clarissa Notariano Biotto², Sheyla Mara Baptista Serra

\section{RESUMO:}

O processo de orçamentação para licitação de uma obra pública ocorre por meio da composição de custos unitários e pesquisa de preços dos insumos registrados em planilhas orçamentárias. A fase inicial deste processo é o levantamento dos quantitativos de materiais e serviços extraídos dos diferentes projetos do edifício. Normalmente, o levantamento é realizado de forma manual e pode apresentar-se falho. Ciente disso e sabendo da importância da avaliação de custos para um empreendimento público, somado à obrigatoriedade do Building Information Modelling (BIM) em obras públicas a partir de 2021, neste trabalho estudou-se a aplicação do BIM para extração de quantitativos e precificação vinculada com as especificações do Sistema Nacional de Pesquisa de Custos e Índices da Construção Civil (SINAPI). O método de pesquisa utilizado foi o estudo de caso de uma obra pública. Para isso, utilizou-se documentos da licitação, como a planilha orçamentária inicial e o projeto básico de arquitetura em CAD 2D. Foram feitas duas modelagens BIM: a primeira para a extração de quantitativos e comparação com dados da licitação; e a segunda para compor diretamente os custos da alvenaria estrutural baseado nos serviços do SINAPI. Por fim, o estudo demonstrou similaridade entre quantitativos extraídos do modelo BIM com o processo manual para a licitação, porém, para se utilizar os dados de custos do SINAPI é necessário que o modelo seja elaborado visando, especificamente, a orçamentação.

PALAVRAS-CHAVE: extração de quantitativos; estimativa de custo; SINAPI; obra pública; construção civil.

\section{ABSTRACT:}

The budgeting process for biding a public project occurs through the method of composition of unit costs using and research of prices of the inputs recorded in budget spreadsheets. The initial step of this process is the materials and services quantity take-off from drawings of the project. Usually, this process is performed manually and might be flawed. Aware of this and knowing the importance of cost evaluation for a public project, added to the mandatory use of Building Information Modelling (BIM) in public projects from 2021 onwards, in this work it was studied the application of BIM for quantitative take-off and budgeting based on specifications of the National System for Research of Costs and Indices for Civil Construction (SINAPI). The research method used was the case study of a public project. For this, bidding documents and 2D CAD projects were used. Two BIM models were developed: the first for quantities take-off and comparison with the bidding data; and the second to compose the costs of the structural masonry based on SINAPI. Finally, the study demonstrated similarity between quantities extracted from the BIM model with the manual bidding process, however, to use SINAPI cost data, it is necessary that the model be prepared with a specific focus on budgeting.

KEYWORDS: quantities take-off; cost estimation; SINAPI; public project; construction industry.
Fonte de Financiamento:

Programa Nacional de Pós

Doutorado (PNPD) da

Coordenação de

Aperfeiçoamento de Pessoal

de Nivel Superior (CAPES)

Conflito de Interesse:

Declara não haver.

Ética em Pesquisa:

Declara não haver

necessidade.

Submetido em: 29/05/2020 Aceito em: 18/12/2020 


\section{INTRODUÇÃO}

Tradicionalmente, a orçamentação de um projeto de construção ocorre por meio do uso de planilhas de custos alimentadas com dados quantitativos retirados manualmente dos desenhos 2D do projeto multiplicados pela unidade de custo de material, equipamento, mão-de-obra e assim por diante (ABANDA et al., 2017). Esse processo de levantamento de quantitativos, muitas vezes, pode conter erros, o que pode afetar a tomada de decisão e o desempenho dos negócios de empresas. Alternativamente, o Building Information Modelling (BIM) pode fornecer maior precisão na obtenção de quantitativos, reduzindo seu tempo de execução, uma vez que os dados são extraídos instantaneamente e automaticamente (EASTMAN et al., 2011; WITICOVSKI, 2011; NASSAR, 2012; BRYDE et al., 2013; SMITH, 2014).

O uso do BIM para levantamento de quantitativos e consequente estimativa de custo ou orçamentação é comumente conhecido como BIM 5D. Entretanto, existe esforço de pesquisadores e usuários para definir com maior precisão as possibilidades de uso do modelo BIM (BIM EXCELLENTE, 2020). Diferentes práticas e ferramentas podem ser usadas para determinação dos custos com base em modelos BIM (Cost Estimation), como exportando quantitativos de objetos de construção (Quantity Take-Off), conectando diretamente a ferramenta BIM com o software de estimativa de custos, ou utilizando ferramentas BIM de quantificação (WU et al., 2014).

Para Mattana e Librelotto (2018), a precisão dos quantitativos e custos obtidos por ferramentas BIM depende das atividades que antecedem à orçamentação, tais como: (1) a qualidade do modelo; (2) o nível de detalhamento das informações do modelo; (3) a forma como o modelo foi desenvolvido; (4) a experiência do orçamentista; e (5) a facilidade ou dificuldade de auditoria da quantidade obtida no modelo.

Assim, a precisão das informações depende da qualidade da modelagem. De acordo com Winter (2017), uma das principais etapas durante a implantação do BIM para orçamentos é a verificação da qualidade da extração dos dados dos quantitativos, pois em caso de imprecisão, pode-se levar a uma distorção do orçamento, interferindo na viabilidade econômica do empreendimento.

Espera-se uma ampliação do uso do BIM no Brasil a partir dos próximos anos, pois conforme afirmado pelo Governo Brasileiro, o uso do BIM se tornará obrigatório nas licitações dos empreendimentos do setor público a partir de 2021 (BRASIL, 2019). Outra orientação governamental desde 2003 é que é obrigatória a utilização do Sistema Nacional de Pesquisa de Custos e Índices da Construção Civil (SINAPI) para obtenção de custos de obras públicas federais, sendo que mensalmente há disponibilização de custos de composições de serviços e preços para aquisição de materiais e equipamentos e contratação de serviços e mão-de-obra (CAIXA, 2020). No entanto, a adoção das planilhas do SINAPI no processo de modelagem BIM para extração de quantitativos e estimativa de custo não tem sido suficientemente explorada na literatura, tornando-se necessária a discussão de boas práticas de modelagem.

Com base nisso, esta pesquisa tem dois objetivos: (1) comparar a precisão da modelagem BIM com o método tradicional de extração de quantitativos; e, (2) estudar as adaptações no modelo BIM e em seus parâmetros para que se possa utilizar as composições do SINAPI para orçamentação do serviço de alvenaria estrutural por meio do software de modelagem BIM.

Portanto, esse artigo apresenta um estudo de caso de uma obra pública no qual foi estudada a modelagem BIM para extração de quantitativos e sua comparação com o método tradicional; e em detalhe, a modelagem BIM da alvenaria estrutural para se aplicar as composições de custo do SINAPI. O artigo é baseado em Andrade (2020) e Andrade et al. (2020). 


\section{ORÇAMENTAÇÃO COM BASE NO SINAPI}

O orçamento da obra expressa os custos necessários para a realização de um empreendimento, de acordo com um plano de execução previamente estabelecido (LIMMER, 1997). Ele é uma das primeiras informações que o empreendedor deseja conhecer para determinar a viabilidade do projeto como negócio (GOLDMAN, 2004).

Já o processo de elaboração de orçamentos, ou orçamentação, tradicionalmente é realizado pelo levantamento dos serviços a serem executados, seus quantitativos e seus respectivos preços unitários (MATTOS, 2006). Esses dados podem ser trabalhados em planilhas eletrônicas ou softwares de orçamentação. A quantificação é feita, normalmente, de maneira manual utilizando-se desenhos 2D, processo sujeito ao erro humano, tendendo a propagar imprecisões e consumir uma considerável parcela de tempo. Com o avanço do BIM, surgem também experiências do seu uso para que os orçamentos possam ser elaborados a partir do modelo.

Os orçamentos das obras públicas federais preparados para as licitações seguem a maioria das composições dos serviços constantes do "Catálogo de Composições Analíticas" disponível no site da Caixa Econômica Federal (CAIXA, 2019). O Catálogo possui em torno de cinco mil composições, que incluem serviços que empregam tecnologias recentes ou novos insumos.

Por exemplo, existem várias classificações de serviços para execução da alvenaria estrutural que podem ser de blocos de concreto ou cerâmicos. O Caderno Técnico do Grupo Alvenaria Estrutural Blocos Cerâmicos (CAIXA, 2017) apresenta trinta e duas composições de alvenaria estrutural que utilizam duas modulações de bloco cerâmico: família de $40(14 \times 19 \times 39 \mathrm{~cm})$ e família de 30 (14×19x29 cm). Para a definição das composições, considerou-se também que a produtividade da mão de obra é influenciada pelo tamanho da parede, pela existência ou não de aberturas, pelo tipo de ferramenta utilizada e pelas condições de preparo da argamassa de assentamento.

A Figura 1 esquematiza a adoção dos cinco níveis de detalhamento deste serviço de alvenaria que precisam ser definidos para se determinar a composição unitária correspondente e obter a planilha de composição unitária do elemento (CAIXA, 2017): (1) Tamanho do bloco; (2) Área líquida; (3) Presença de vãos; (4) Ferramenta para espalhar argamassa de assentamento; e, (5) Forma de preparo da massa. No caso da Figura 1, as opções assinaladas em negrito correspondem à composição "01.PARE.AECE.012/02: alvenaria estrutural de blocos cerâmicos 14x19x39 (espessura de $14 \mathrm{~cm}$ ), para paredes com área líquida maior ou igual a $6 \mathrm{~m}^{2}$, com vãos, utilizando colher de pedreiro e argamassa de assentamento com preparo manual, unidade $\mathrm{m}^{2}$. A Tabela 1 apresenta o detalhamento dessa composição.

Portanto, vê-se que é necessário saber mais do que as características geométricas das paredes para pode utilizar o SINAPI na orçamentação de obras públicas: necessita-se saber o procedimento de execução da alvenaria estrutural no canteiro de obras.

Para que o orçamentista possa definir a composição a ser utilizada, ele deve buscar informações junto ao projetista, ao caderno de especificações, ou arbitragem própria. Para Lima (2018), a arbitragem pode se basear na experiência e em buscar escolher a composição no SINAPI que seja a mais viável tecnicamente.

Segundo Silva e Pereira (2019), a variabilidade de composições no SINAPI faz com que ocorra um aumento no tempo necessário para a orçamentação, pois o orçamentista deve analisar as diferenças nas composições, conforme os níveis de definições, para tomar a decisão de qual composição escolher. 
Figura 1. Especificação de Alvenaria Estrutural Blocos cerâmicos

Fonte: CAIXA, 2017
Tabela 1. Descrição da 01.PARE.AECE.012/02 unidade $\mathrm{m}^{2}$

Fonte: CAIXA, 2017

\begin{tabular}{|c|c|c|c|c|}
\hline Item & Código & Descrição & Unid. & Coef. \\
\hline $\mathrm{C}$ & 87367 & $\begin{array}{c}\text { Argamassa traço 1:1:6 (cimento, cal e areia média) para } \\
\text { emboço/massa única/assentamento de alvenaria de } \\
\text { vedação, preparo manual. Af_06/2014 }\end{array}$ & $\mathrm{m}^{3}$ & 0,018000 \\
\hline $\mathrm{C}$ & 88309 & Pedreiro com encargos complementares & $\mathrm{h}$ & 0,960000 \\
\hline C & 88316 & Servente com encargos complementares & $\mathrm{h}$ & 0,480000 \\
\hline I & 38603 & $\begin{array}{l}\text { Bloco estrutural cerâmico } 14 \times 19 \times 34 \mathrm{~cm}, 6,0 \mathrm{MPa}(\mathrm{NBR} \\
15270)\end{array}$ & un & 0,720000 \\
\hline 1 & 34588 & $\begin{array}{l}\text { Bloco estrutural cerâmico } 14 \times 19 \times 39 \mathrm{~cm}, 6,0 \mathrm{MPa}(\mathrm{NBR} \\
15270)\end{array}$ & un & 9,370000 \\
\hline 1 & 38548 & $\begin{array}{l}\text { Canaleta estrutural cerâmica, 14×19x19 cm, 6,0 MPa } \\
\text { (NBR 15270) }\end{array}$ & un & 0,120000 \\
\hline 1 & 34655 & $\begin{array}{l}\text { Canaleta estrutural cerâmica, 14x19×39 cm, 6,0 MPa } \\
\text { (NBR 15270) }\end{array}$ & un & 2,160000 \\
\hline I & 34781 & $\begin{array}{l}\text { Meio bloco estrutural cerâmico 14x19x19 cm, 6,0 MPa } \\
\text { (NBR 15270) }\end{array}$ & un & 1,440000 \\
\hline 1 & 34547 & $\begin{array}{l}\text { Tela de aço soldada galvanizada/zincada para alvenaria, } \\
\text { fio } d=* 1,2 \text { a } 1,7^{*} \mathrm{~mm} \text {, malha } 15 \times 15 \mathrm{~mm},(\mathrm{C} \times \mathrm{L}) * 50 \times 12^{*} \\
\mathrm{~cm}\end{array}$ & $\mathrm{~m}$ & 0,395000 \\
\hline
\end{tabular}

\section{MODELAGEM BIM PARA EXTRAÇÃO DE QUANTITATIVOS E ESTIMATIVA DE CUSTO}

A modelagem BIM 5D é comumente atribuída ao uso de modelos BIM para estimativas de custos de projeto. Ao contrário de atribuir dimensões de informações aos modelos BIM (por exemplo, 4D, 5D, 6D etc.), o BIM Excellence elaborou uma lista contendo a taxonomia de cento e vinte e cinco usos de modelos BIM (BIM EXCELLENCE, 2020). Sob o código 4130 - Quantity Take-off , a extração de quantitativos acontece quando modelos BIM são utilizados para calcular o quantitativo de mobiliário, acessórios e equipamentos, ou mesmo materiais de construção com o propósito de gerar uma estimativa de custo. Já a estimativa de custo - código 4070 - Cost Estimation - se refere ao uso de modelos BIM para gerar estudos de viabilidade e comparar diferentes opções de orçamentos (BIM EXCELLENCE, 2020). 
A modelagem BIM utilizada para extração de quantitativos e preparação de orçamento de empreendimentos de construção se mostra mais acurada e assertiva quando comparada aos métodos tradicionais baseados em desenhos 2D do empreendimento (MONTEIRO e MARTINS, 2013; CHAREF et al., 2018), pois está menos propensa a erros de alteração e indefinições de projeto.

A modelagem BIM 5D pode ser conduzida de três maneiras (EASTMAN et al., 2011):

1. Por meio de exportação de quantitativos do modelo BIM para um software de orçamentação;

2. Pela vinculação do software BIM com o software de orçamentação; e,

3. Por meio de ferramenta BIM específica para levamento de quantitativos e orçamentação.

Nos três fluxos de trabalho supracitados, é necessário que o grau de desenvolvimento da modelagem dos elementos construtivos seja compatível com o grau de precisão que se espera atingir no orçamento (FELISBERTO, 2017). Apesar dos benefícios da automatização no levantamento de quantitativos, a literatura mostra que a modelagem BIM não é tão direta e automática quanto se imagina para orçamentação (SABOL, 2008; MONTEIRO e MARTINS, 2013; SAKAMORI, 2015; FELISBERTO, 2017; WINTER, 2017; FENATO et al., 2018).

Os elementos inseridos no modelo BIM podem ter seus quantitativos extraídos, entretanto, diversos elementos não existirão no modelo, total ou parcialmente, e necessitarão ser computados de alguma forma. Diversos serviços podem não ser modelados, mas podem ser quantificados com base em outro elemento já modelado, como por exemplo, a fiação elétrica que pode ser relacionada ao comprimento dos eletrodutos (SAKAMORI, 2015). 0 que não constar no modelo BIM, necessita ser computado por vias tradicionais, "como administração local, mobilização, desmobilização, ensaios técnicos, aquisição do terreno, empresa gerenciadora etc." (FELISBERTO, 2017).

Por outro lado, serviços temporários, como escoramento e fôrmas de estruturas de concreto, podem ser modelados em BIM, e assim, ter seus quantitativos extraídos (NEIVA NETO e RUSCHEL, 2015). Portanto, é necessário definir previamente à modelagem BIM quais elementos construtivos irão compor o modelo e em qual nível de detalhe (SABOL, 2008). Além disso, a abordagem da modelagem precisa ser ajustada às ferramentas BIM, estruturas do projeto e padrões de medição para se otimizar o desempenho da orçamentação e garantir a consistência dos resultados (MONTEIRO e MARTINS, 2013).

A Tabela 2 apresenta diversos trabalhos que exploram o uso de modelos BIM para orçamentação no contexto brasileiro. Nessas pesquisas, diferentes softwares foram empregados, como Autodesk Revit, ArchiCAD, SketchUp, Autodesk Navisworks Manage, Microsoft Excel e alguns plug-ins e softwares de orçamentação. Todos esses estudos encontraram resultados semelhantes: aumento da precisão dos quantitativos extraídos; aumento da confiabilidade; automatização na atualização dos quantitativos conforme alteração de projeto; entre outros. 
Tabela 2. Trabalhos sobre BIM para orçamentação

Fonte: Autores

\begin{tabular}{|c|c|c|}
\hline Trabalho & $\begin{array}{l}\text { Software } \\
\text { Utilizado }\end{array}$ & Principais Resultados \\
\hline $\begin{array}{l}\text { Andrade } \\
(2012)\end{array}$ & $\begin{array}{l}\text { Autodesk } \\
\text { Revit }\end{array}$ & $\begin{array}{l}\text { Maior exatidão com a extração automática das tabelas de quantitativos; } \\
\text { Maior necessidade de reflexão sobre a tecnologia da construção; } \\
\text { Evolução da forma de projetar visando eficiência no processo. }\end{array}$ \\
\hline $\begin{array}{l}\text { Mendes Jr. et } \\
\text { al. (2013) }\end{array}$ & $\begin{array}{l}\text { Autodesk } \\
\text { Revit }\end{array}$ & $\begin{array}{c}\text { Inseriram códigos da composição SINAPI e da EAP na modelagem BIM e } \\
\text { exportaram tabelas para manipular no Excel. }\end{array}$ \\
\hline $\begin{array}{l}\text { Monteiro e } \\
\text { Martins } \\
(2013)\end{array}$ & ArchiCAD & $\begin{array}{l}\text { Testaram o ArchiCAD para extração de quantitativos e orçamentação. } \\
\text { Viram diversas limitações na ferramenta para cumprir com padrões de } \\
\text { medição, e outros resultados desejados. }\end{array}$ \\
\hline $\begin{array}{l}\text { Costa e Serra } \\
\qquad(2014)\end{array}$ & SketchUp & $\begin{array}{l}\text { Utilização do modelo 3D auxilia na eliminação de erros manuais comuns } \\
\text { na fase de levantamento de quantitativos. Alguns elementos não foram } \\
\text { modelados. }\end{array}$ \\
\hline Piropo (2014) & $\begin{array}{l}\text { Autodesk } \\
\text { Revit, } \\
\text { Autodesk } \\
\text { Navisworks } \\
\text { Manage, } \\
\text { Excel } \\
\end{array}$ & $\begin{array}{l}\text { Explorou o uso de ferramentas BIM para modelagem 3D, 4D e 5D para } \\
\text { elaboração de orçamento executivo com custo e planejamento } \\
\text { associados. }\end{array}$ \\
\hline Braga (2015) & $\begin{array}{l}\text { Autodesk } \\
\text { Revit }\end{array}$ & $\begin{array}{c}\text { O BIM pode fornecer a quantificação exata e automatizada de } \\
\text { componentes. O BIM ajuda na redução significativa da variabilidade das } \\
\text { estimativas de custos. }\end{array}$ \\
\hline $\begin{array}{l}\text { Melhado e } \\
\text { Pinto (2015) }\end{array}$ & $\begin{array}{l}\text { Autodesk } \\
\text { Revit, Vico } \\
\text { Office }\end{array}$ & $\begin{array}{l}\text { Apresentaram as facilidades da modelagem BIM para extração de } \\
\text { quantitativos comparado ao método tradicional, bem como as limitações } \\
\text { do ferramental BIM. }\end{array}$ \\
\hline $\begin{array}{l}\text { Sakamori } \\
\text { (2015) }\end{array}$ & $\begin{array}{l}\text { Autodesk } \\
\text { Revit, MS } \\
\text { Excel }\end{array}$ & $\begin{array}{l}\text { Trabalhou com códigos da composição SINAPI e da EAP na modelagem } \\
\text { BIM e exportou tabelas para manipular no Excel. Mostrou que diversos } \\
\text { itens necessitam ser acrescidos manualmente ao orçamento por não } \\
\text { constar no modelo 3D. }\end{array}$ \\
\hline $\begin{array}{l}\text { Carvalho e } \\
\text { Pinto (2015) }\end{array}$ & $\begin{array}{l}\text { Autodesk } \\
\text { Revit, } \\
\text { SISPLO }\end{array}$ & $\begin{array}{l}\text { Criaram um template básico com famílias do sistema e componentes já } \\
\text { cadastrados com regras que ligassem às composições do SINAPI. Uso de } \\
\text { Plug-in SISPLO para conexão com software de orçamentação com mesmo } \\
\text { nome. }\end{array}$ \\
\hline $\begin{array}{l}\text { Felisberto } \\
\text { (2017) }\end{array}$ & $\begin{array}{l}\text { Autodesk } \\
\text { Revit, } \\
\text { Autodesk } \\
\text { Navisworks } \\
\text { Manage, } \\
\text { MS Excel } \\
\end{array}$ & $\begin{array}{l}\text { Contribuições para elaboração de orçamento de referência de obra } \\
\text { pública com uso da modelagem BIM em nível de desenvolvimento até } \\
\text { 300. Testou diferentes métodos de modelagem para aplicar a } \\
\text { metodologia de árvore de fatores do SINAPI. Encontrou diversas } \\
\text { limitações que puderam ser parcialmente superadas no software BIM. }\end{array}$ \\
\hline Winter (2017) & $\begin{array}{l}\text { Autodesk } \\
\text { Revit }\end{array}$ & $\begin{array}{c}\text { Propôs um método para o planejamento da modelagem BIM para } \\
\text { elaboração de orçamento analítico. Principal barreira para uso do BIM na } \\
\text { orçamentação é a falta de planejamento do modelo e a comunicação } \\
\text { entre os envolvidos. }\end{array}$ \\
\hline Lima (2018) & $\begin{array}{l}\text { Autodesk } \\
\text { Revit, } \\
\text { Sigma } \\
\text { Estimates, } \\
\text { MS Excel }\end{array}$ & $\begin{array}{l}\text { Testou dois fluxos de trabalho diferentes: 1. Extração de quantitativos } \\
\text { para o Excel, e confeç̧ão do orçamento via tradicional; } 2 \text {. Sincronização } \\
\text { do modelo BIM e o software de orçamento BIM via plug-in para Revit. } \\
\text { Verificou-se a necessidade de planejar o processo de modelagem. }\end{array}$ \\
\hline $\begin{array}{l}\text { Fenato et al. } \\
\text { (2018) }\end{array}$ & $\begin{array}{l}\text { Autodesk } \\
\text { Revit }\end{array}$ & $\begin{array}{l}\text { Proposição de um método de modelagem BIM para orçamento } \\
\text { operacional. Identificação de diversas limitações do software para atender } \\
\text { as especificidades do orçamento. }\end{array}$ \\
\hline $\begin{array}{c}\text { Benazzi e } \\
\text { Freire (2019) }\end{array}$ & ArchiCAD & Constante atualização dos dados à medida que o projeto é alterado. \\
\hline $\begin{array}{l}\text { Senna et al. } \\
(2019)\end{array}$ & $\begin{array}{c}\text { Autodesk } \\
\text { Revit }\end{array}$ & $\begin{array}{l}\text { O BIM é eficiente para a extração de quantitativos desde que o modelo } \\
\text { seja desenvolvido com o LOD adequado. }\end{array}$ \\
\hline
\end{tabular}


No que tange o uso de BIM na orçamentação para licitação de obras públicas federais, ou seja, nas quais é obrigatório o uso do SINAPI, a CAIXA aconselha o uso do software Autodesk Revit para modelagem das disciplinas de arquitetura e estrutura atribuindo os códigos SINAPI (CAIXA, 2020). 0 órgão público também sugere o uso de template para configuração do modelo (CAIXA, 2020) e até mesmo de plug-in e software específico para orçamentação (CARVALHO e PINTO, 2015). De modo expresso, a CAIXA (2020) propõe um fluxo de trabalho conforme:

A extração de quantitativos é feita a partir do modelo em tabelas Autodesk Revit $\circledast$ e posterior organização da planilha em Microsoft Excel®. O Autodesk Revit $\AA_{\text {tem }}$ função principal de modelar e gerar quantitativos, sendo necessário o uso de planilha eletrônica para revisão dos quantitativos, bem como sua associação às referências técnicas do SINAPI. (CAIXA, 2000)

É sabido que um dos princípios fundamentais do processo de modelagem BIM é a manutenção de ambiente colaborativo e aberto, no qual os envolvidos escolham livremente o software que desejam trabalhar. Apesar da sugestão da CAIXA pelo uso do software Autodesk Revit, no qual foi produzido plug-in e template no software mencionado, entende-se como necessário que a CAIXA expanda o oferecimento de templates para demais softwares de modelagem BIM. Com isso, visa-se que o desenvolvimento de modelos continue acontecendo de forma colaborativa, em ambiente aberto e não-proprietário, entre o número maior de projetistas.

Apesar da existência de trabalhos nacionais sobre o uso de modelos BIM para levantamento de quantitativos e orçamentação, os mesmos foram desenvolvidos no fluxo de trabalho 2 ou 3 (como especificado por EASTMAN et al., 2011 supracitado), ou seja, com uso de software específico de orçamento vinculado a modelo BIM ou com software de modelagem BIM para fins de extração e orçamentação. Esses trabalhos não utilizaram software de modelagem para atribuir os custos unitários. Portanto, os modelos utilizados podem não ter sido preparados objetivando o orçamento de referência para licitação no contexto de obras públicas. Tendo em vista a crescente relevância para a discussão da relação BIM-SINAPI, fez-se necessária a realização de um trabalho que contemple essa abordagem e não somente as vantagens do BIM na extração de quantitativos.

\section{MÉTODO DE PESQUISA}

O processo de pesquisa (vide Figura 3) iniciou-se com a revisão bibliográfica sobre modelagem BIM para extração de quantitativos e orçamentação, orçamento na construção civil, e aplicação do SINAPI em obras públicas. Para isso, foram utilizadas publicações em base de dados disponíveis online, compostos por artigos, monografias, teses, dissertações e livros sobre os temas.

A estratégia de pesquisa adotada nesta investigação foi o estudo de caso, o qual pretende explorar em detalhes e grande profundidade um fenômeno em seu contexto real (YIN, 2015). Os pesquisadores selecionaram o edifício de uma instituição pública como objeto do estudo de caso. Trata-se de um projeto de construção pública, com uma área total de construção de $200 \mathrm{~m}^{2}$ feito em alvenaria estrutural, contendo quatro grandes salas de suporte à pesquisa e ensino, dois banheiros, uma copa e área de serviço, conforme Figura 2. As paredes apresentam revestimento cerâmico com 1,60 m de altura nas áreas molhadas (banheiros e área de serviço) e pintura nas demais áreas. Todo o piso interno foi concebido em granilite com a presença de rodapé, também em granilite. A laje de forro foi executada com vigota pré-moldada e lajota cerâmica com $13 \mathrm{~cm}$ de espessura. 
Figura 2. Planta Baixa da Edificação

Fonte: Arquivos de projeto presentes na documentação de licitação

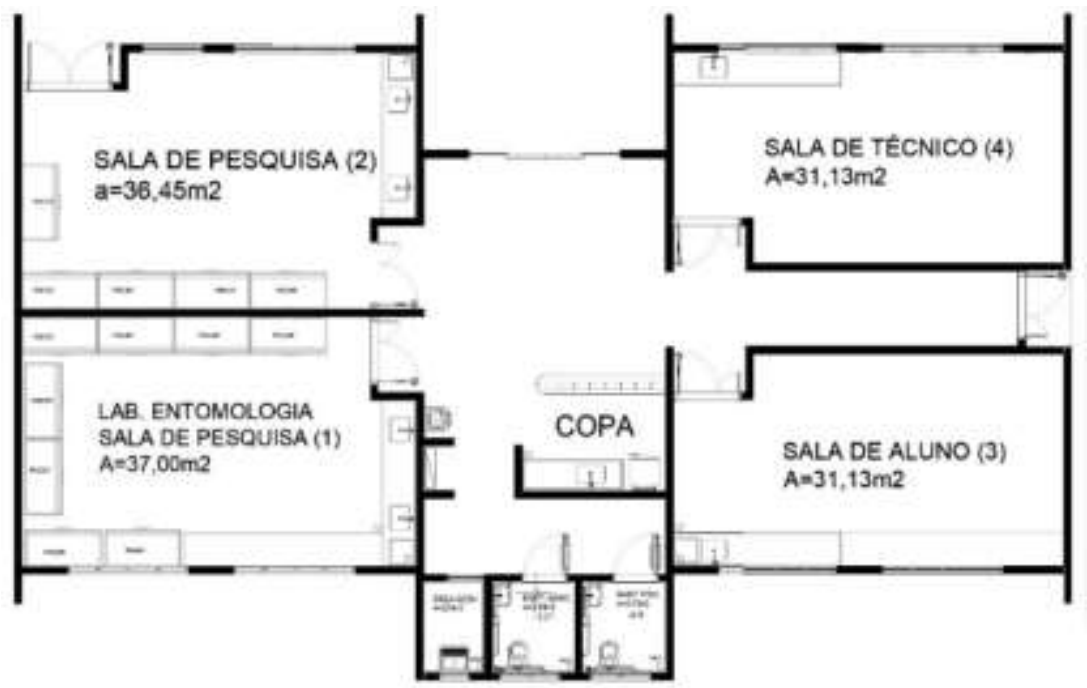

O estudo de caso ocorreu em duas etapas de modelagem BIM denominadas: I e II. O software escolhido para modelagem BIM foi o Autodesk Revit 2019 por ser o indicado pela CAIXA.

Na etapa de modelagem BIM - I, um primeiro modelo BIM foi desenvolvido com base nos desenhos CAD do projeto, especificações, detalhes e memoriais coletados junto ao setor de projetos do órgão público. Nessa etapa foram modelados os seguintes elementos construtivos: fundação, alvenaria estrutural (modelada como Parede Empilhada), piso, esquadrias, laje e telhado. Em seguida, fez-se a extração e comparação entre os quantitativos do modelo BIM com os dados da licitação conforme constam na Planilha de Composições Unitárias. Para tornar o trabalho mais simplificado, a comparação de resultados limitou-se aos seguintes quantitativos e/ou serviços:

- Volume de concreto dos blocos e baldrames;

- Área de contrapiso e granilite;

- Área de paredes e revestimentos (alvenaria, chapisco, massa única, pintura, emboço e revestimento cerâmico);

- Área de telhado;

- Comprimento de rodapé.

Nesse primeiro modelo não foi possível aplicar o SINAPI por limitações do software BIM para extração de quantitativos de alvenarias compostas por paredes empilhadas, portanto, uma nova modelagem BIM fez-se necessária. Na etapa seguinte de modelagem BIM - II, foi dado foco ao serviço de alvenaria, cujas paredes foram modeladas com nível de detalhamento conceitual para se poder aplicar os parâmetros de composição de custos da alvenaria estrutural referenciados no SINAPI. Os resultados de ambas as etapas foram analisados e suas contribuições enfatizadas. 


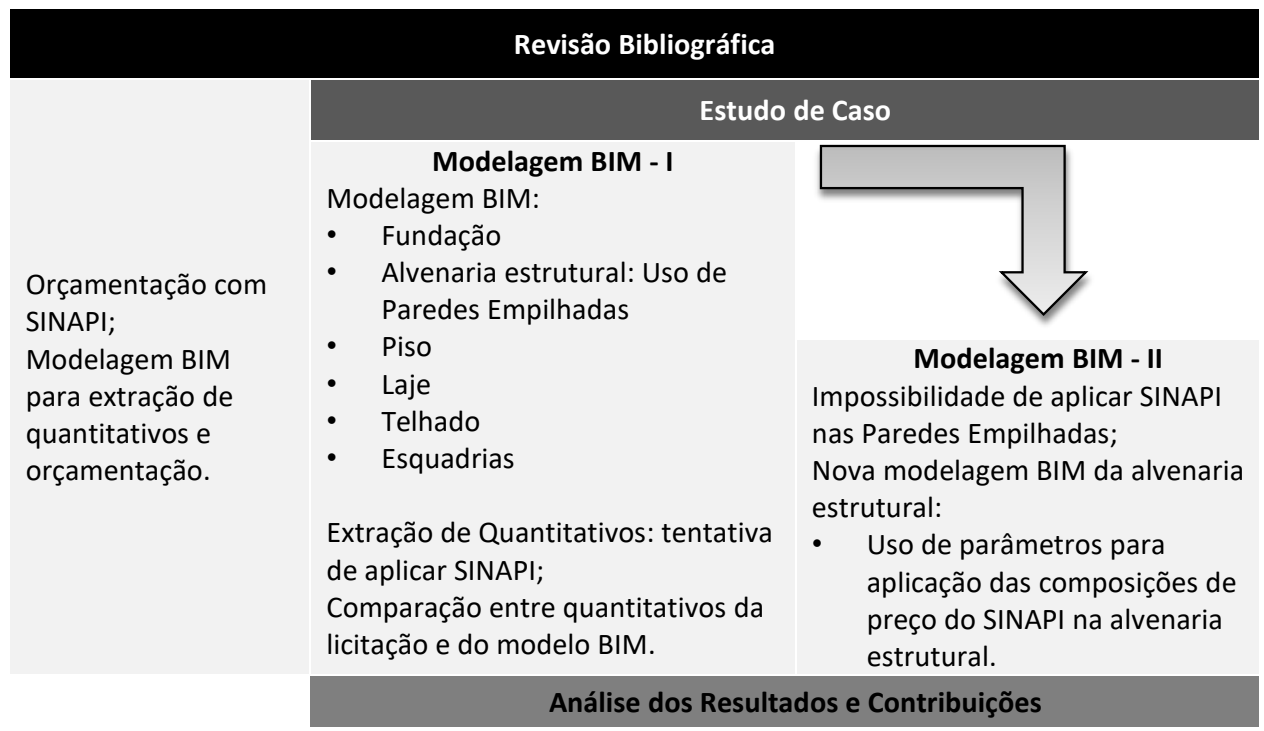

\section{RESULTADOS}

\section{MODELAGEM BIM - I}

A primeira modelagem BIM para extração de quantitativos seguiu a sequência construtiva da execução da edificação (Figura 4). Havia outros elementos para serem modelados, mas optouse por simplificar a comparação para fins de realização deste trabalho.
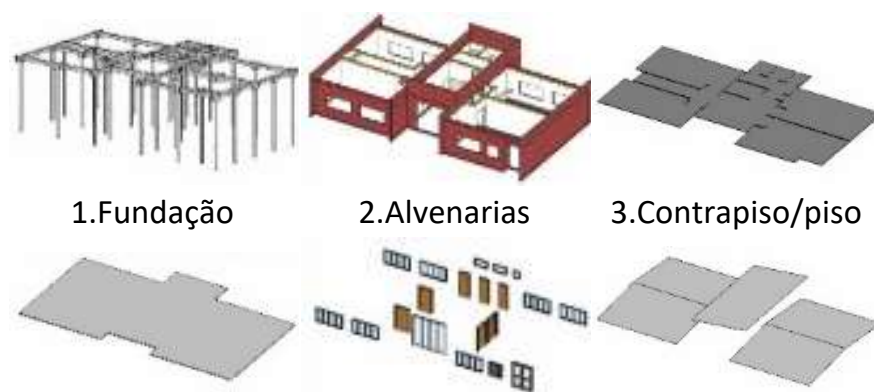

4.Laje Coberta

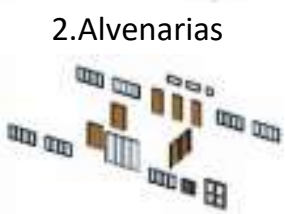

5.Esquadrias

\section{Contrapiso/piso}

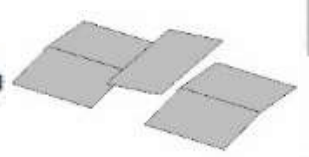

6. Telhado

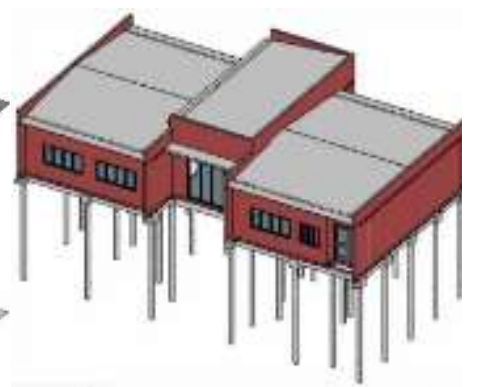

Modelo BIM - I
Figura 4. Sequência de Modelagem BIM

Fonte:

Autores

Para modelar as alvenarias foi necessário estudar as camadas de revestimento e acabamentos que o núcleo de bloco cerâmico receberia durante a execução. Foram identificados seis serviços: chapisco, emboço, massa única, revestimento cerâmico, rodapé e pinturas interna e externa. Para se obter o quantitativo dos revestimentos, considerou-se que a modelagem da alvenaria seria em camadas relacionadas com os serviços seguintes. Ou seja, devido às diversas variações de altura e das camadas de revestimento nas faces das alvenarias, se optou por modelar as paredes por meio da ferramenta "Empilhamento de Paredes" (Stacked Wall). Essa ferramenta permite criar uma alvenaria composta pelo empilhamento de diferentes tipos paredes. Desse modo, foram modelados onze perfis de paredes com diferentes camadas de revestimentos, conforme apresentado na Tabela 3. 
Tabela 3. Tipos de paredes e suas camadas de revestimento no Modelo BIM - I

Fonte: Autores
Figura 5. Exemplo de empilhamento de paredes no Modelo BIM - I

Fonte: Adaptado de Andrade (2020)

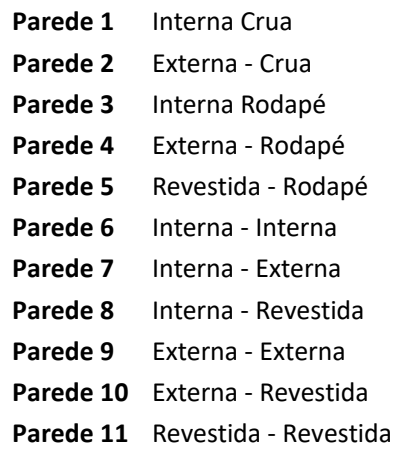

\begin{tabular}{|c|c|c|c|c|c|c|}
\hline \multicolumn{7}{|c|}{ Camadas de Revestimento } \\
\hline & & Chapisco & Núcleo & Chapisco & & \\
\hline Pintura Externa & Massa & Chapisco & Núcleo & Chapisco & & \\
\hline Rodapé & Massa & Chapisco & Núcleo & Chapisco & Massa & Rodapé \\
\hline Pintura Externa & Massa & Chapisco & Núcleo & Chapisco & Massa & Rodapé \\
\hline Cerâmica & Emboço & Chapisco & Núcleo & Chapisco & Massa & Rodapé \\
\hline Pintura Interna & Massa & Chapisco & Núcleo & Chapisco & Massa & Pintura Interna \\
\hline Pintura Interna & Massa & Chapisco & Núcleo & Chapisco & Massa & Pintura Externa \\
\hline Pintura Interna & Massa & Chapisco & Núcleo & Chapisco & Emboço & Cerâmica \\
\hline Pintura Externa & Massa & Chapisco & Núcleo & Chapisco & Massa & Pintura Externa \\
\hline Pintura Externa & Massa & Chapisco & Núcleo & Chapisco & Emboço & Cerâmica \\
\hline Cerâmica & Emboço & Chapisco & Núcleo & Chapisco & Emboço & Cerâmica \\
\hline
\end{tabular}

Para exemplificar este tipo de processo de modelagem, considera-se uma parede interna que divide um ambiente interno seco e um ambiente interno molhado. $\mathrm{Na}$ face do ambiente seco tem-se: 0,05 m de parede chapiscada; e 3,00m de parede com massa única e pintura. Na face do ambiente molhado tem-se: $0,05 \mathrm{~m}$ de parede chapiscada; $1,60 \mathrm{~m}$ de parede com emboço e revestimento cerâmico; e, 1,40m de parede com massa única e pintura. Então, para se obter esse perfil de alvenaria, se empilhou a Parede 1 - Interna Crua; sobre ela a Parede 8 - Interna Revestida; e, sobre essa, a Parede 6 - Interna Interna (vide Figura 5).

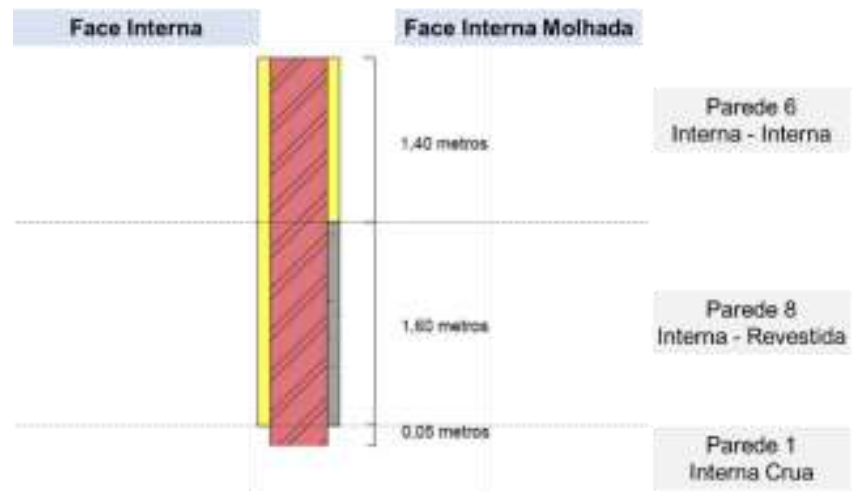

No total, o empilhamento dos onze tipos de paredes em diferentes combinações de alturas ou cotas formaram as alvenarias do projeto, conforme Figura 6, e representadas na Tabela 4.

Figura 6. Distribuição das paredes empilhadas na planta

Fonte: Adaptado de Andrade (2020)

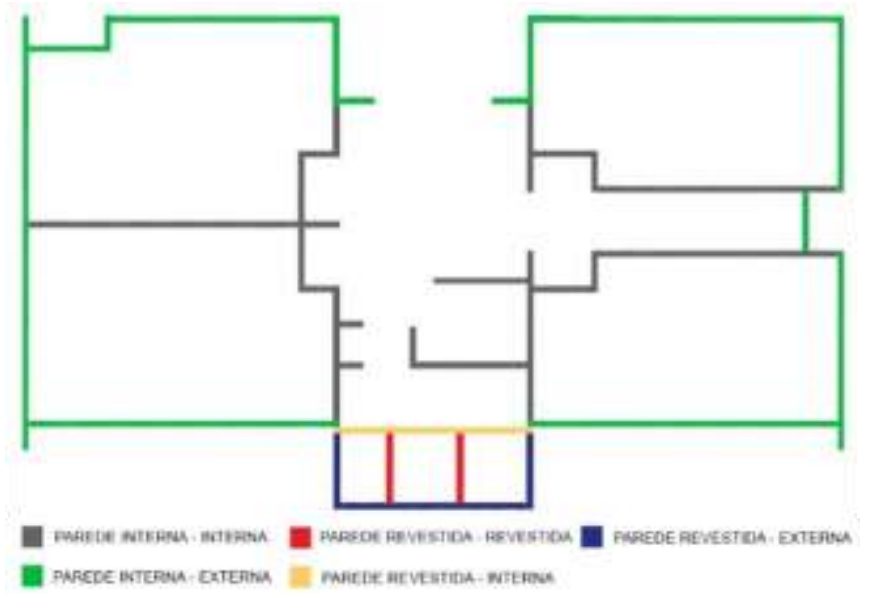




\begin{tabular}{c|c|c|c|c|c|c|c|c|c}
\hline \multicolumn{2}{c|}{ Interna-Interna } & \multicolumn{2}{|c|}{ Interna-Externa } & \multicolumn{2}{c|}{$\begin{array}{c}\text { Interna- } \\
\text { Revestida }\end{array}$} & \multicolumn{2}{c}{$\begin{array}{c}\text { Externa- } \\
\text { Revestida }\end{array}$} & \multicolumn{2}{c}{$\begin{array}{c}\text { Revestida- } \\
\text { Revestida }\end{array}$} \\
\hline $\begin{array}{c}\text { Tipo de } \\
\text { Parede }\end{array}$ & $\begin{array}{c}\text { Cota } \\
(\mathbf{m})\end{array}$ & $\begin{array}{c}\text { Tipo de } \\
\text { Parede }\end{array}$ & $\begin{array}{c}\text { Cota } \\
(\mathbf{m})\end{array}$ & $\begin{array}{c}\text { Tipo de } \\
\text { Parede }\end{array}$ & $\begin{array}{c}\text { Cota } \\
(\mathbf{m})\end{array}$ & $\begin{array}{c}\text { Tipo de } \\
\text { Parede }\end{array}$ & $\begin{array}{c}\text { Cota } \\
(\mathbf{m})\end{array}$ & $\begin{array}{c}\text { Tipo de } \\
\text { Parede }\end{array}$ & $\begin{array}{c}\text { Cota } \\
(\mathbf{m})\end{array}$ \\
\hline $\begin{array}{c}\text { Interna - } \\
\text { Interna }\end{array}$ & $\begin{array}{c}\text { Até o } \\
\text { topo }\end{array}$ & $\begin{array}{c}\text { Interna- } \\
\text { Externa }\end{array}$ & $\begin{array}{c}\text { Até o } \\
\text { topo }\end{array}$ & $\begin{array}{c}\text { Interna - } \\
\text { Interna }\end{array}$ & $\begin{array}{c}\text { Até o } \\
\text { topo }\end{array}$ & $\begin{array}{c}\text { Interna } \\
\text { Externa }\end{array}$ & $\begin{array}{c}\text { Até o } \\
\text { topo }\end{array}$ & $\begin{array}{c}\text { Interna - } \\
\text { Interna }\end{array}$ & $\begin{array}{c}\text { Até o } \\
\text { topo }\end{array}$ \\
\hline $\begin{array}{c}\text { Interna } \\
\text { Rodapé }\end{array}$ & 0,12 & $\begin{array}{c}\text { Externa } \\
\text { Rodapé }\end{array}$ & 0,12 & $\begin{array}{c}\text { Interna } \\
\text { Revestida }\end{array}$ & 1,6 & $\begin{array}{c}\text { Externa } \\
\text { Revestida }\end{array}$ & 1,6 & $\begin{array}{c}\text { Revestida - } \\
\text { Revestida }\end{array}$ & 1,6 \\
\hline $\begin{array}{c}\text { Interna } \\
\text { Crua }\end{array}$ & 0,05 & $\begin{array}{c}\text { Externa } \\
\text { Crua }\end{array}$ & 0,05 & $\begin{array}{c}\text { Interna } \\
\text { Rodapé }\end{array}$ & 0,12 & $\begin{array}{c}\text { Externa } \\
\text { Rodapé }\end{array}$ & 0,12 & $\begin{array}{c}\text { Interna } \\
\text { Rodapé }\end{array}$ & 0,12 \\
\hline
\end{tabular}

Tabela 4. Cotas das variações de paredes empilhadas

Fonte:

Andrade, 2020
Durante a Modelagem BIM - I, percebeu-se a importância de seguir a sequência construtiva no processo de modelagem, a fim de obter quantitativos mais precisos. A comparação entre o Modelo BIM - I e a planilha orçamentária da licitação mostrou uma pequena diferença de valores de ambos os métodos, conforme retratado na Tabela 5. Embora pareça uma pequena diferença entre os métodos, essas quantidades podem aumentar em projetos maiores e mais complexos. Notou-se também uma diferença de quantitativo maior em Pintura Externa (5,99\%), Chapisco (2,47\%), Revestimento Cerâmico e Emboço (ambos -2,40\%) ocasionada por indefinições de altura de tais revestimentos no projeto em CAD.

\begin{tabular}{|c|c|c|c|c|c|c|}
\hline \multirow{3}{*}{$\begin{array}{l}\text { Categorias } \\
\text { Fundação }\end{array}$} & \multirow{2}{*}{$\begin{array}{c}\text { Nome } \\
\text { Bloco de concreto }\end{array}$} & \multicolumn{2}{|c|}{$\begin{array}{l}\text { Quantitativo do } \\
\text { Modelo BIM - I }\end{array}$} & \multicolumn{2}{|c|}{$\begin{array}{c}\text { Quantitativo da } \\
\text { Licitação }\end{array}$} & \multirow[t]{2}{*}{$\begin{array}{c}\text { Diferença } \\
\text { Relativa }\end{array}$} \\
\hline & & 5,00 & $\mathrm{~m}^{3}$ & - & & \\
\hline & Vigas baldrame & 8,16 & $\mathrm{~m}^{3}$ & - & & \\
\hline & Total & 13,16 & $\mathrm{~m}^{3}$ & 13,10 & $m^{3}$ & $0,46 \%$ \\
\hline \multirow{8}{*}{ Paredes } & Blocos de alvenaria estrutural & 462,00 & $\mathrm{~m}^{2}$ & 466,00 & $m^{2}$ & $-0,86 \%$ \\
\hline & Chapisco & 871,00 & $m^{2}$ & 850,00 & $m^{2}$ & $2,47 \%$ \\
\hline & Massa & 806,00 & $\mathrm{~m}^{2}$ & 806,36 & $m^{2}$ & $-0,04 \%$ \\
\hline & Emboço & 41,00 & $\mathrm{~m}^{2}$ & 43,68 & $m^{2}$ & $-2,40 \%$ \\
\hline & Pintura interna & 433,00 & $\mathrm{~m}^{2}$ & 427,68 & $\mathrm{~m}^{2}$ & $1,24 \%$ \\
\hline & Pintura externa & 356,00 & $\mathrm{~m}^{2}$ & 378,68 & $m^{2}$ & $-5,99 \%$ \\
\hline & Revestimento cerâmico & 41,00 & $m^{2}$ & 43,68 & $m^{2}$ & $-2,40 \%$ \\
\hline & Rodapé & 142,11 & $m$ & 144,63 & $\mathrm{~m}$ & $-1,74 \%$ \\
\hline \multirow{4}{*}{ Pisos } & Contrapiso & 201,00 & $\mathrm{~m}^{2}$ & 200,97 & $m^{2}$ & $0,01 \%$ \\
\hline & Granilite & 201,00 & $\mathrm{~m}^{2}$ & 200,97 & $\mathrm{~m}^{2}$ & $0,01 \%$ \\
\hline & Laje & 225,00 & $\mathrm{~m}^{2}$ & 225,00 & $\mathrm{~m}^{2}$ & $0,00 \%$ \\
\hline & Revestimento laje & 207,00 & $\mathrm{~m}^{2}$ & 209,00 & $m^{2}$ & $-0,96 \%$ \\
\hline Telhado & Telhas & 236,00 & $\mathrm{~m}^{2}$ & 235,78 & $m^{2}$ & $0,09 \%$ \\
\hline \multirow{2}{*}{\multicolumn{2}{|c|}{ Total }} & 4235,27 & $\mathrm{~m}^{2}$ & 4245,53 & $m^{2}$ & $-10.26 \%$ \\
\hline & & \multicolumn{4}{|c|}{ Média de diferença } & $-0.72 \%$ \\
\hline
\end{tabular}

MODELAGEM BIM - ॥

Após a extração dos quantitativos do modelo BIM - I, se tentou aplicar as especificações do SINAPI para determinar o custo $/ \mathrm{m}^{2}$ da alvenaria estrutural, para fins de comparação com o orçamento da licitação expresso na Tabela 6. 0 orçamentista arbitrou que os serviços seriam executados com palheta e a argamassa de assentamento seria produzida em betoneira. Entretanto, para determinar o custo sobre as alvenarias era preciso que o modelo apresentasse
Tabela 5. Exemplo de categorias dos quantitativos analisados

Fonte:

Andrade, 2020 
Figura 6. Perspectiva do Modelo BIM - II

Fonte: Andrade, 2020 as informações de área líquida e presença ou não de aberturas nas paredes. Essas informações não foram possíveis de extrair da alvenaria modelada como paredes empilhadas, pois o software não fornece o quantitativo de uma alvenaria que seja composta por diversas paredes empilhadas; o software só extrai quantitativos de elementos individuais, e não do conjunto que esses elementos formam. Assim, foi necessário criar um segundo modelo (BIM - II) contendo apenas paredes simples, como mostra a Figura 7.

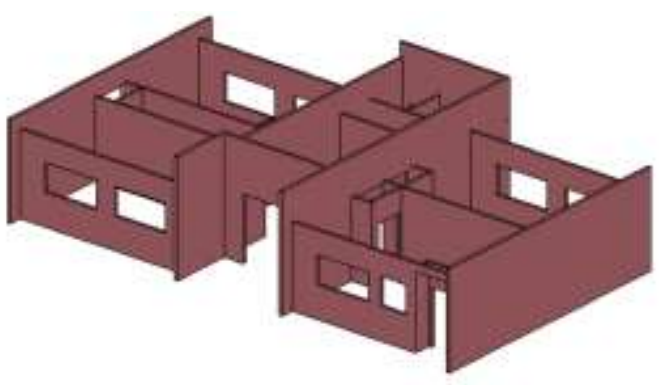

Tabela 6. Quantitativos e custos da alvenaria estrutural extraídos da planilha de licitação

Fonte: Arquivos de orçamento presentes na documentação de licitação

\begin{tabular}{|c|c|c|c|c|c|c|c|}
\hline 4 & Paredes & Código & $\begin{array}{c}\text { Compo- } \\
\text { sição }\end{array}$ & $\begin{array}{l}\text { Quan- } \\
\text { tidade }\end{array}$ & $\begin{array}{l}\text { Uni- } \\
\text { dade }\end{array}$ & $\begin{array}{l}\text { Custo } \\
\text { Unitá } \\
\text {-rio }\end{array}$ & $\begin{array}{l}\text { Custo } \\
\text { (R\$) }\end{array}$ \\
\hline 4.1 .1 & $\begin{array}{l}\text { Alvenaria estrutural de blocos } \\
\text { cerâmicos } 14 \times 19 \times 29 \text {, (espessura de } 14 \\
\mathrm{~cm} \text { ), para paredes com área líquida } \\
\text { menor que } 6 \mathrm{~m}^{2} \text {, sem vãos, utilizando } \\
\text { palheta e argamassa de assentamento } \\
\text { com preparo em betoneira. } \\
\text { Af_12/2014 }\end{array}$ & 89290 & SINAPI & 27,23 & $\mathrm{~m}^{2}$ & 57,16 & $1.556,47$ \\
\hline 4.1 .2 & $\begin{array}{l}\text { Alvenaria estrutural de blocos } \\
\text { cerâmicos } 14 \times 19 \times 29 \text {, (espessura de } 14 \\
\mathrm{~cm} \text { ), para paredes com área líquida } \\
\text { maior ou igual a } 6 \mathrm{~m}^{2} \text {, sem vãos, } \\
\text { utilizando palheta e argamassa de } \\
\text { assentamento com preparo em } \\
\text { betoneira. Af_12/2014 }\end{array}$ & 89292 & SINAPI & 211,51 & $\mathrm{~m}^{2}$ & 52,75 & $11.157,15$ \\
\hline 4.1 .3 & $\begin{array}{l}\text { Alvenaria estrutural de blocos } \\
\text { cerâmicos } 14 \times 19 \times 29 \text {, (espessura de } 14 \\
\mathrm{~cm} \text { ), para paredes com área líquida } \\
\text { menor que } 6 \mathrm{~m}^{2} \text {, com vãos, utilizando } \\
\text { palheta e argamassa de assentamento } \\
\text { com preparo em betoneira. } \\
\text { Af_12/2014 }\end{array}$ & 89294 & SINAPI & 13,27 & $\mathrm{~m}^{2}$ & 63,15 & 838,00 \\
\hline \multirow[t]{2}{*}{4.1 .4} & $\begin{array}{l}\text { Alvenaria estrutural de blocos } \\
\text { cerâmicos } 14 \times 19 \times 29 \text {, (espessura de } 14 \\
\mathrm{~cm} \text { ), para paredes com área líquida } \\
\text { maior ou igual a } 6 \mathrm{~m}^{2} \text {, com vãos, } \\
\text { utilizando palheta e argamassa de } \\
\text { assentamento com preparo em } \\
\text { betoneira. Af_12/2014 }\end{array}$ & 89296 & SINAPI & 214,15 & $\mathrm{~m}^{2}$ & 56,18 & $12.030,95$ \\
\hline & TOTAL & & & 466,16 & $\mathrm{~m}^{2}$ & & $25.582,57$ \\
\hline
\end{tabular}


Neste segundo modelo BIM, automatizou-se a deteç̧ão de vãos na alvenaria, porém, o software utilizado não tem essa funcionalidade pronta, pois o mesmo não desconta a área dos vãos. Portanto, um novo parâmetro foi criado para calcular por custo $/ \mathrm{m}^{2}$ de cada parede segundo as especificações do SINAPI apresentada na Tabela 6. Nesse novo parâmetro se estabeleceu que se houvessem vãos na parede, atribuía-se o valor 1 , caso contrário atribuía-se valor 0 . Em seguida, foram selecionadas todas as paredes com abertura e atribuído o valor 1 ao parâmetro abertura. Nota-se que esse foi um procedimento manual e visual para selecionar apenas as paredes com abertura. 0 mesmo foi feito para paredes sem abertura, com valor 0 para $o$ parâmetro.

Além de novos parâmetros, o software BIM também permite criar colunas nas tabelas de quantitativos, e dentro da caixa de diálogo é possível atribuir fórmulas e equações a essas colunas. Tais fórmulas puderam ser escritas usando os valores dos parâmetros existentes como base. Assim, o valor do custo unitário para cada parede foi inserido com o uso de equações. Para a criação de uma nova coluna deve-se seguir os passos: Propriedades de Tabela > Campos > Adicionar Parâmetro Calculado (Figura 8).

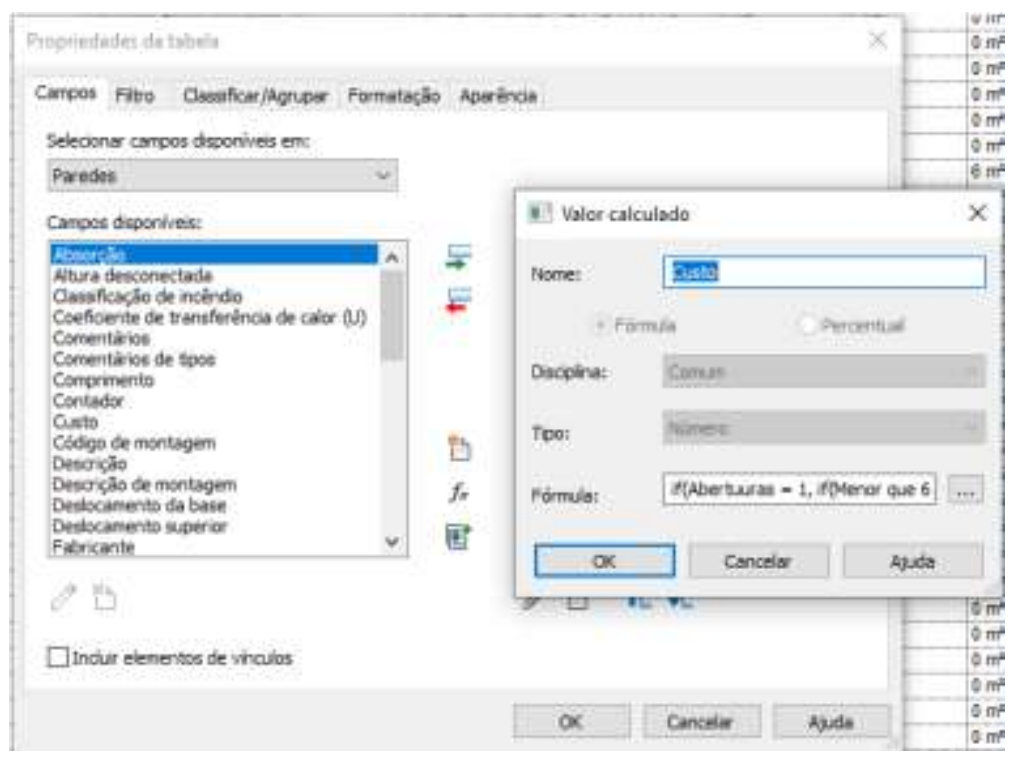

Na caixa de diálogo "Valor Calculado" pode-se atribuir um nome para a coluna e definir a equação. Foi utilizada a seguinte equação para definir o custo.

$$
\operatorname{Se}(\text { Abertura=1,Se(Área>6,56.18,63.15),Se(Área<6,57.16,52.75)). }
$$

A planilha com os dados de quantitativos e custo da alvenaria extraída no modelo BIM - II é apresentada na Tabela 7.

Os dados do orçamento da licitação utilizados para comparação estão descritos na Tabela 6, conforme mencionado. 0 custo total da alvenaria estrutural alcançada no Modelo BIM - II foi de $\mathrm{R} \$ 25.807,38$, valor muito próximo ao da planilha orçamentária da licitação, ou seja, $\mathrm{R} \$ 25.582,87$. A diferença relativa é inferior a 1\%. Embora a área líquida em ambos os métodos (BIM e manual) tenha sido a mesma, $466,16 \mathrm{~m}^{2}$, a pequena diferença encontrada no custo final deve-se às diferenças entre os critérios de classificação das paredes nos quatro grupos apresentados na Tabela 6 .
Figura 8. Criação de Parâmetro Calculado

Fonte:

Andrade, 2020 
Tabela 7. Quantitativos e custos da alvenaria estrutural extraídos do modelo BIM - II

Fonte: Autores

\begin{tabular}{|c|c|c|c|c|c|c|c|}
\hline Área & Aberturas & $\begin{array}{l}\text { Maior que } \\
6 \mathrm{~m}^{2} \text { com } \\
\text { abertura }\end{array}$ & $\begin{array}{c}\text { Menor que } \\
6 \mathrm{~m}^{2} \text { com } \\
\text { abertura }\end{array}$ & \begin{tabular}{|c|} 
Maior que \\
$6 \mathrm{~m}^{2}$ sem \\
abertura \\
\end{tabular} & \begin{tabular}{|c|} 
Menor que \\
$6 \mathrm{~m}^{2}$ sem \\
abertura
\end{tabular} & $\begin{array}{c}\text { Custo } \\
\left(\mathrm{R} \$ / \mathrm{m}^{2}\right)\end{array}$ & $\begin{array}{l}\text { Valor total } \\
\text { (R\$) }\end{array}$ \\
\hline $2,04 \mathrm{~m}^{2}$ & 0 & \multirow{9}{*}{$0,00 \mathrm{~m}^{2}$} & \multirow{9}{*}{$0,00 \mathrm{~m}^{2}$} & \multirow{9}{*}{$0,00 \mathrm{~m}^{2}$} & $2,04 \mathrm{~m}^{2}$ & \multirow{9}{*}{57,16} & 116,61 \\
\hline $2,04 \mathrm{~m}^{2}$ & 0 & & & & $2,04 \mathrm{~m}^{2}$ & & 116,61 \\
\hline $2,08 \mathrm{~m}^{2}$ & 0 & & & & $2,08 \mathrm{~m}^{2}$ & & 118,88 \\
\hline $2,40 \mathrm{~m}^{2}$ & 0 & & & & $2,40 \mathrm{~m}^{2}$ & & 137,18 \\
\hline $2,58 \mathrm{~m}^{2}$ & 0 & & & & $2,58 \mathrm{~m}^{2}$ & & 147,76 \\
\hline $3,06 \mathrm{~m}^{2}$ & 0 & & & & $3,06 \mathrm{~m}^{2}$ & & 174,97 \\
\hline $3,06 \mathrm{~m}^{2}$ & 0 & & & & $3,06 \mathrm{~m}^{2}$ & & 174,91 \\
\hline $3,06 \mathrm{~m}^{2}$ & 0 & & & & $3,06 \mathrm{~m}^{2}$ & & 174,91 \\
\hline $3,06 \mathrm{~m}^{2}$ & 0 & & & & $3,06 \mathrm{~m}^{2}$ & & 174,91 \\
\hline Subtotal & & & & & $23,38 \mathrm{~m}^{2}$ & & $1.336,74$ \\
\hline $6,15 \mathrm{~m}^{2}$ & 0 & \multirow{8}{*}{$0,00 \mathrm{~m}^{2}$} & \multirow{8}{*}{$0,00 \mathrm{~m}^{2}$} & $6,15 \mathrm{~m}^{2}$ & \multirow{8}{*}{$0,00 \mathrm{~m}^{2}$} & \multirow{8}{*}{52,75} & 324,62 \\
\hline $6,15 \mathrm{~m}^{2}$ & 0 & & & $6,15 \mathrm{~m}^{2}$ & & & 324,62 \\
\hline $8,51 \mathrm{~m}^{2}$ & 0 & & & $8,51 \mathrm{~m}^{2}$ & & & 448,90 \\
\hline $10,20 \mathrm{~m}^{2}$ & 0 & & & $10,20 \mathrm{~m}^{2}$ & & & 538,05 \\
\hline $20,94 \mathrm{~m}^{2}$ & 0 & & & $20,94 \mathrm{~m}^{2}$ & & & 1104,75 \\
\hline $21,42 \mathrm{~m}^{2}$ & 0 & & & $21,42 \mathrm{~m}^{2}$ & & & 1129,86 \\
\hline $26,08 \mathrm{~m}^{2}$ & 0 & & & $26,08 \mathrm{~m}^{2}$ & & & 1375,61 \\
\hline $49,10 \mathrm{~m}^{2}$ & 0 & & & $49,10 \mathrm{~m}^{2}$ & & & 2589,92 \\
\hline Subtotal & & & & $148,55 \mathrm{~m}^{2}$ & & & $7.836,33$ \\
\hline $1,50 \mathrm{~m}^{2}$ & 1 & \multirow{5}{*}{$0,00 \mathrm{~m}^{2}$} & $1,50 \mathrm{~m}^{2}$ & \multirow{5}{*}{$0,00 \mathrm{~m}^{2}$} & \multirow{5}{*}{$0,00 \mathrm{~m}^{2}$} & \multirow{5}{*}{63,15} & 94,51 \\
\hline $2,22 \mathrm{~m}^{2}$ & 1 & & $2,22 \mathrm{~m}^{2}$ & & & & 140,00 \\
\hline $2,69 \mathrm{~m}^{2}$ & 1 & & $2,69 \mathrm{~m}^{2}$ & & & & 170,06 \\
\hline $2,78 \mathrm{~m}^{2}$ & 1 & & $2,78 \mathrm{~m}^{2}$ & & & & 175,42 \\
\hline $5,90 \mathrm{~m}^{2}$ & 1 & & $5,90 \mathrm{~m}^{2}$ & & & & 372,81 \\
\hline Subtotal & & & $15,09 \mathrm{~m}^{2}$ & & & & 952,80 \\
\hline $9,16 \mathrm{~m}^{2}$ & 1 & $9,16 \mathrm{~m}^{2}$ & \multirow{12}{*}{$0,00 \mathrm{~m}^{2}$} & \multirow{12}{*}{$0,00 \mathrm{~m}^{2}$} & \multirow{12}{*}{$0,00 \mathrm{~m}^{2}$} & \multirow{12}{*}{56,18} & 514,72 \\
\hline $10,64 \mathrm{~m}^{2}$ & 1 & $10,64 \mathrm{~m}^{2}$ & & & & & 597,55 \\
\hline $13,50 \mathrm{~m}^{2}$ & 1 & $13,50 \mathrm{~m}^{2}$ & & & & & 758,43 \\
\hline $16,32 \mathrm{~m}^{2}$ & 1 & $16,32 \mathrm{~m}^{2}$ & & & & & 916,96 \\
\hline $17,33 \mathrm{~m}^{2}$ & 1 & $17,33 \mathrm{~m}^{2}$ & & & & & 973,45 \\
\hline $22,28 \mathrm{~m}^{2}$ & 1 & $22,28 \mathrm{~m}^{2}$ & & & & & 1251,79 \\
\hline $22,28 \mathrm{~m}^{2}$ & 1 & $22,28 \mathrm{~m}^{2}$ & & & & & 1251,85 \\
\hline $22,28 \mathrm{~m}^{2}$ & 1 & $22,28 \mathrm{~m}^{2}$ & & & & & 1251,90 \\
\hline $23,6 \mathrm{~m}^{2}$ & 1 & $23,60 \mathrm{~m}^{2}$ & & & & & 1325,94 \\
\hline $32,78 \mathrm{~m}^{2}$ & 1 & $32,78 \mathrm{~m}^{2}$ & & & & & 1841,49 \\
\hline $44,16 \mathrm{~m}^{2}$ & 1 & $44,16 \mathrm{~m}^{2}$ & & & & & 2481,01 \\
\hline $44,79 \mathrm{~m}^{2}$ & 1 & $44,79 \mathrm{~m}^{2}$ & & & & & 2516,42 \\
\hline Subtotal & & $279,12 \mathrm{~m}^{2}$ & & & & & $15.681,51$ \\
\hline $466,16 \mathrm{~m}^{2}$ & & $279,13 \mathrm{~m}^{2}$ & $15,09 \mathrm{~m}^{2}$ & $148,56 \mathrm{~m}^{2}$ & $23,39 \mathrm{~m}^{2}$ & & $25.807,38$ \\
\hline
\end{tabular}

Destaca-se a importância de relacionar corretamente o custo de cada composição SINAPI para o orçamento de obras públicas. Caso se considerasse uma única composição (sem variações do custo devido às aberturas e tamanho da parede), o custo final mais barato seria $\mathrm{R} \$ 24.589,94$ e o mais caro seria $\mathrm{R} \$ 29.438,00$. A diferença entre os valores é de, aproximadamente, $20 \%$. Dessa maneira, é de fundamental importância que a modelagem seja realizada considerando todos os parâmetros do SINAPI para que o orçamento apresente um valor mais próximo da realidade e mais coerente para o órgão público. 


\section{DISCUSSÃO DOS RESULTADOS}

A ideia inicial do trabalho foi a de criar um único modelo BIM do qual fosse possível extrair tanto os quantitativos quanto compor os custos da alvenaria estrutural baseados nas referências do SINAPI. A extração de quantitativos ocorreu de maneira rápida e precisa, entretanto, para aplicar os dados do SINAPI, o modelo BIM - I criado inicialmente não foi eficaz devido ao uso da ferramenta "Parede Empilhada". Como o uso dessa ferramenta consiste no empilhamento de diferentes perfis de paredes, houve um problema com a extração dos quantitativos individuais de cada parede. Portanto, houve uma limitação da modelagem utilizada que gerou um retrabalho na modelagem BIM em relação ao elemento "alvenaria estrutural".

Entretanto, na segunda modelagem BIM - II surgiu uma nova limitação do software: não foi possível identificar automaticamente as alvenarias com vãos, o que necessitou a criação de um novo parâmetro para cumprir essa função. Em seguida, foi mandatório encontrar e selecionar no modelo todas as alvenarias com aberturas, e digitar 1 (presença de vãos) no campo do novo parâmetro. Esse processo foi simples devido à baixa complexidade do projeto. Entretanto, ao generalizar sua aplicação em empreendimentos mais complexos, o processo pode se mostrar inviável pela confiabilidade da obtenção do orçamento em função das alterações possíveis no elemento "alvenaria estrutural".

Outro ponto importante a ressaltar sobre a modelagem BIM para orçamentação com uso do SINAPI é a necessidade de se conhecer antecipadamente o procedimento construtivo, ou seja, no caso da "alvenaria estrutural" qual o tipo de bloco utilizado, o método de preparação da argamassa e o método de aplicação da argamassa de assentamento dos blocos cerâmicos, a fim de incorporar essa informação no modelo. Afinal, os " $n$ " modelos BIM devem fornecer suporte à integração de dados e possibilitar uma análise de projeto além das características geométricas (EASTMAN et al., 2011).

Portanto, ainda é necessário estudar novas estratégias para a modelagem BIM para facilitar a extração dos quantitativos e a estimativa dos custos tendo por base o uso das composições unitárias de custo do SINAPI.

\section{CONCLUSÕES}

Esta pesquisa analisou o uso do modelo BIM visando os processos de extração de quantitativos e de estimativa dos custos de um empreendimento público de duas formas diferentes. A primeira modelagem com a ferramenta "Parede empilhada", impossibilitou a obtenção dos custos via composições unitárias do SINAPI. Entretanto, para a comparação dos quantitativos entre o método tradicional utilizado na licitação e o modelo BIM, não se verificou diferença significativa entre os mesmos.

No entanto, ao tentar utilizar o mesmo modelo BIM para obtenção do custo da alvenaria estrutural com base nas especificações do SINAPI, as paredes que foram modeladas empilhadas não puderam ser utilizadas para checar área líquida e presença ou ausência de vãos. Portanto, foi necessário desenvolver um segundo e mais simples modelo BIM adicionando novos parâmetros para calcular os custos $/ \mathrm{m}^{2}$ da parede.

Mesmo utilizando um modelo simplificado, por mais simples que seja a planta da edificação, verifica-se dificuldade em definir os tipos possíveis de serviços de elevação da alvenaria na intenção de se fazer a extração automática de quantitativos ou de custos nas duas modelagens estudadas. 
O artigo visa contribuir para a discussão de que modelar em BIM para extrair quantitativos é diferente de modelar para orçamentação. Mesmo em empreendimentos privados, as construtoras podem desenvolver composições e custos de serviços próprios que não sejam "facilmente" incorporadas ao modelo 3D.

Nesse estudo se intencionou não utilizar softwares específicos de modelagem BIM para extração de quantitativos e orçamentação, e nem planilhas eletrônicas posteriores para aplicação do custo unitário. Portanto, ambos processos de levantamento de quantitativos e estimativa de custo foram realizados dentro do software Autodesk Revit via aplicação de parâmetro e fórmula. Essa seria uma alternativa para fazer estudos rápidos de viabilidade.

Outra constatação do artigo é a necessidade de se integrar o processo de orçamentação durante a concepção do modelo da edificação, de forma a se utilizar apenas um único modelo BIM para a extração de quantitativos e estimativa de custos de acordo com as referências do SINAPI. Sem essa definição prévia, podem ser gerados retrabalhos e esforços para adequação dos modelos existentes. Assim, conclui-se que a atual forma de licitação de projetos públicos com base nas composições de custo do SINAPI requer maiores esforços de modelagem por parte dos projetistas, de forma a utilizar o mesmo modelo BIM para os processos de extração de quantitativos e de estimativa de custos.

\section{Agradecimentos}

Este trabalho foi financiado pela Coordenação de Aperfeiçoamento de Pessoal de Nível Superior (CAPES) via Programa Nacional de Pós-Doutorado (PNPD), processo no 88887.363128/2019-00.

\section{Referências Bibliográficas}

ABANDA, F.H.; KAMSU-FOGUEM, B.; TAH, J.H.M. BIM - New rules of measurement ontology for construction cost estimation. Engineering Science and Technology, An International Journal. V.20, n.2. p. 443-459. abr. 2017. DOI: https://doi.org/10.1016/j.jestch.2017.01.007

ANDRADE, F. M. R. Estudo do BIM na Orçamentação de Edificações Públicas com Uso do SINAPI. 2020. 53 f. Trabalho de Conclusão de Curso (Graduação) - Curso de Engenharia Civil, Departamento de Engenharia Civil, Universidade Federal de São Carlos, São Carlos, 2020.

ANDRADE, F. M. R.; BIOTTO, C. N.; SERRA, S. M. B. Estudo do BIM 5D para orçamentação de um projeto público com uso do SINAPI. In: Encontro Nacional de Tecnologia do Ambiente Construído (ENTAC), 18., 2020, Porto Alegre. Anais [...]. Porto Alegre: ANTAC, 2020. Disponível em: https://entac2020.com.br/anais-2020/artigos/574.pdf

ANDRADE, L. S. A contribuição dos sistemas BIM para o planejamento orçamentário das obras públicas: estudo de caso do auditório e da biblioteca de Planaltina. Dissertação (Mestrado em Arquitetura e Urbanismo) - Universidade de Brasília, Brasília, 2012.

BENAZZI JUNIOR, L. A.; FREIRE, F. Avaliação de quantitativos e planejamento de custos utilizando processo BIM. In: Simpósio Brasileiro de Tecnologia da Informação e Comunicação na Construção (SBTIC), 2., 2019, Campinas, SP. Anais [...]. Porto Alegre: ANTAC, 2019. Disponível em: https://antaceventos.net.br/index.php/sbtic/sbtic2019/paper/view/139

BIM EXCELLENCE. BIM Dictionary. Disponível em: https://bimdictionary.com/. Acesso em: 04 ago. 2020. 
BRAGA, P. R. Levantamento de quantitativos com uso da tecnologia BIM. 2015. 130f. Trabalho de Conclusão de Curso (Graduação) - Curso de Engenharia Civil, Escola Politécnica, Universidade Federal da Bahia, Salvador, 2015.

BRASIL. Decreto n. 9.983, de 22 de agosto de 2019. Dispõe sobre a Estratégia Nacional de Disseminação do Building Information Modelling e institui o Comitê Gestor da Estratégia do Building Information Modelling. Disponível em: http://www.planalto.gov.br/ccivil 03/ Ato20192022/2019/Decreto/D9983.htm

BRYDE, D.; BROQUETAS, M.; MARCVOLM, J. The project benefits of Building Information Modelling (BIM). International Journal of Project Management. v.31, i.7, p. 971-980. out. 2013. DOI: https://doi.org/10.1016/j.ijproman.2012.12.001

CAIXA ECONÔMICA FEDERAL. SINAPI: Metodologias e Conceitos: Sistema Nacional de Pesquisa de Custos e Índices da Construção Civil. 8a Ed. Brasília: CAIXA, 2020. Disponível em http://www.caixa.gov.br/Downloads/sinapi-manual-de-metodologias-e-

conceitos/Livro1 SINAPI Metodologias e Conceitos 8 Edicao.pdf

CAIXA ECONÔMICA FEDERAL. SINAPI: Catálogo de Composições Analíticas. 2019. Disponível em http://www.caixa.gov.br/Downloads/sinapi-catalogo-de-composicoesanaliticas/CATALOGO COMPOSICOES ANALITICAS EXCEL 07 2019.xIs

CAIXA ECONÔMICA FEDERAL. Caderno Técnico do Grupo Alvenaria Estrutural Blocos Cerâmicos. 2017. Disponível em: http://www.caixa.gov.br/Downloads/sinapi-composicoes-aferidas-lote1habitacao-fundacoes-estruturas/SINAPI CT MT1 ALV ESTRUTURAL CERAMICO v002.pdf

CARVALHO, R.R.; PINTO, D.S. Utilização do Revit para geração de orçamentos de referência utilizando a base de dados do SINAPI. 2015. Autodesk University Brasil 2015. Disponível em: https://custom.cvent.com/FDBB345248B94F40BFFFCEF2FBE054E4/files/3e750d34ac4949ac9bbe7 8d50293b4bd.pdf.

CHAREF, R.; ALAKA, H.; EMMITT, S. Beyond the third dimension of BIM: A systematic review of literature and assessment of professional views. Journal of Building Engineering. v.19, p. 242-257. set. 2018. DOI: https://doi.org/10.1016/j.jobe.2018.04.028

COSTA, J.M.C.; SERRA, S. M. B. Comparação de processos de levantamento de quantitativos: tradicional e BIM In: Encontro Nacional de Tecnologia do Ambiente Construído (ENTAC), 15., 2014, Maceió, Anais [...]. ENTAC, nov. 2014.

EASTMAN, C.M.; TEICHOLZ, P.; SACKS, R.; LISTON, K. BIM Handbook: A Guide to Building Information Modeling for Owners, Managers, Designers, Engineers and Contractors. Hoboken: Wiley, 2011.

FELISBERTO, A. D. Contribuições para elaboração de orçamento de referência de obra pública observando a nova árvore de fatores do SINAPI com BIM 5D - LOD 300. Dissertação (Mestrado). 2017. Universidade Federal de Santa Catarina, Centro Tecnológico, Programa de Pós-Graduação em Engenharia Civil, Florianópolis. 231f.

FENATO, T. M.; SAFFARO, F. A.; BARISON, M. B.; HEINECK, L. F. M.; SCHEER, S. Método para elaboração de orçamento operacional utilizando um software de autoria BIM. Ambiente Construído, Porto Alegre, v. 18, n. 4, p. 279-299, out./dez. 2018. DOI: http://dx.doi.org/10.1590/s1678$\underline{86212018000400305}$

GOLDMAN, P. Introdução ao planejamento e controle de custos na construção civil brasileira, 4a edição. São Paulo: PINI, 2004. 
LIMA, C.B.M. Como elaborar orçamento utilizando processo BIM. 2018. Trabalho de Conclusão de Curso (Graduação em Engenharia Civil). Faculdade de Tecnologia da Universidade de Brasília, Brasília.

LIMMER, C.V. Planejamento, Orçamentação e Controle de Projetos e Obras. Rio de Janeiro: Livros Técnicos e Científicos Editora S.A., 1997.

MATTANA, L.; LIBRELOTTO, L.I. Estratégias para ensino de orçamentação com adoção de BIM em ambiente acadêmico. Gestão e Tecnologia de Projetos, v.13, n.3, p.97-118, dez. 2018. DOI: http://dx.doi.org/10.11606/gtp.v13i3.139505

MATTOS, A. D. Como preparar orçamentos de obras: dicas para orçamentistas, estudos de caso, exemplos. São Paulo: Pini, 2006.

MELHADO, S.; PINTO A. C. Benefícios e desafios da utilização do BIM para extração de quantitativos. In: IX Simpósio Brasileiro de Gestão e Economia da Construção (SIBRAGEC) e VI Encuentro Latinoamericano de Gestión y Economía de la Construcción (ELAGEC), 2015, São Carlos. Anais [...]. São Carlos, 2015. p.511-518.

MENDES JUNIOR, R.; SCHEER, S.; SANTOS, A. B.; PAULA, F. A.; GOUVEA, L. B. Comunicação do modelo integrado com o planejamento de prazo e custo. In: VI Encontro de Tecnologia da Informação e Comunicação na Construção, 2013, Campinas. Anais [...]. Qualidade de projeto na era digital integrada. Campinas: Unicamp, 2013. v.1. p.1192-1201.

MONTEIRO, A.; MARTINS, J. P. A survey on modeling guidelines for quantity takeoff-oriented BIMbased design. Automation in Construction, v. 35, p. 238-253, nov. 2013. DOI: https://doi.org/10.1016/j.autcon.2013.05.005

NASSAR, K. Assessing Building Information Modeling estimating techniques using data from the classroom. Journal of Professional Issues in Engineering Education and Practice, v.138, p. 171-180 2012. DOI: https://doi.org/10.1061/(ASCE)El.1943-5541.0000101

NEIVA NETO, R. da S.; RUSCHEL, R. C. BIM aplicado ao projeto de fôrmas de madeira em estrutura de concreto armado. Ambiente Construído, Porto Alegre, v. 15, n. 4, p. 183-201, dez. 2015. DOI: https://doi.org/10.1590/s1678-86212015000400046

SABOL, L. Challenges in cost estimating with Building Information Modeling. IFMA World Workplace, p. IFMA World Workplace, 2008.

SAKAMORI, M. M. Modelagem 5D (BIM): processo de orçamentação com estudo sobre controle de custos e valor agregado para empreendimentos de construção civil. 178 f. Dissertação (Mestrado em Engenharia de Construção Civil), Universidade Federal do Paraná, Curitiba, 2015.

SENNA, A.C.; SAUD, D.N.; CASTRO, I.P.de. BIM 5D em obras públicas: estudo de caso comparativo entre métodos de extração de quantitativos em edificação residencial. In: Simpósio Brasileiro de Tecnologia da Informação e Comunicação na Construção (SBTIC), 2019, Campinas. Anais [...]. Porto Alegre: $\quad 2019 . \quad$ Disponível em: https://www.antaceventos.net.br/index.php/sbtic/sbtic2019/paper/view/194

SILVA, R.P.; PEREIRA, S.L. Análise do serviço de chapisco do SINAPI para utilização em projetos BIM. In: Simpósio Brasileiro de Tecnologia da Informação e Comunicação na Construção (SBTIC), 2019, Campinas. Anais [...]. Porto Alegre: ANTAC, 2019. Disponível em: https://www.antaceventos.net.br/index.php/sbtic/sbtic2019/paper/viewFile/138/207

SMITH, P. BIM \& the 5D Project Cost Manager. Procedia - Social And Behavioral Sciences. v.119, p. 475-484. 19 mar. 2014. DOI: https://doi.org/10.1016/j.sbspro.2014.03.053 
WINTER, L.M. Método para o planejamento da modelagem BIM para fins de elaboração do orçamento analítico. 2017. Trabalho de Conclusão de Curso (Graduação em Engenharia Civil). Escola de Engenharia da Universidade Federal do Rio Grande do Sul, Porto Alegre.

WITICOVSKI, L.C. Levantamento de quantitativos em projeto: uma análise comparativa do fluxo de informações entre as representações 2D e o modelo de informações da construção (BIM). Dissertação (Mestrado em Engenharia de Construção Civil). Universidade Federal do Paraná, 2011.

WU, S.; WOOD, G.; GINIGE, K.; JONG, S. W. A technical review of BIM based cost estimating in UK quantity surveying practice, standards, and tools. Journal of Information Technology in Construction. v.19, p. 534-562. dez. 2014. Disponível em: https://www.itcon.org/paper/2014/31.

YIN, R. K. Estudo de Caso: Planejamento e Métodos. Bookman Editora, 2015.
Felipe Miguel Rocha Andrade felipe.andrade@hotmail.com

Clarissa Notariano Biotto clarissa.biotto@ufscar.br

Sheyla Mara Baptista Serra sheylabs@ufscar.br 